\title{
Spatial-Temporal Variation Characteristics and Influencing Factors of Vegetation in the Yellow River Basin from 2000 to 2019
}

\author{
Peirong Shi ${ }^{\dagger}$, Peng Hou ${ }^{\dagger}$, Jixi Gao *, Huawei Wan *, Yongcai Wang and Chenxi Sun \\ Center for Satellite Application on Ecology and Environment, Ministry of Ecology and Environment, \\ Beijing 100094, China; shipeirong@e-mail.secmep.cn (P.S.); houpcy@163.com (P.H.); kbqinfang@163.com (Y.W.); \\ sunchenxi@e-mail.secmep.cn (C.S.) \\ * Correspondence: gjx@nies.org (J.G.); wanhw@secmep.cn (H.W.) \\ + These authors contributed equally to this work.
}

check for updates

Citation: Shi, P.; Hou, P.; Gao, J.; Wan, H.; Wang, Y.; Sun, C. Spatial-Temporal Variation Characteristics and Influencing Factors of Vegetation in the Yellow River Basin from 2000 to 2019. Atmosphere 2021, 12, 1576. https:// doi.org/10.3390/atmos12121576

Academic Editors: Xiangjin Shen and Binhui Liu

Received: 26 October 2021

Accepted: 21 November 2021

Published: 27 November 2021

Publisher's Note: MDPI stays neutral with regard to jurisdictional claims in published maps and institutional affiliations.

Copyright: (c) 2021 by the authors. Licensee MDPI, Basel, Switzerland. This article is an open access article distributed under the terms and conditions of the Creative Commons Attribution (CC BY) license (https:// creativecommons.org/licenses/by/ $4.0 /)$.

\begin{abstract}
Vegetation is a crucial and intuitive index that can be used to evaluate the ecological status. Since the 20th century, land use has changed significantly in Yellow River Basin (YRB), along with great changes of vegetation, serious soil erosion, and gradual ecological deterioration. To improve the ecological environment in the YRB, China has carried out a series of ecological protection projects since the 1970s. Therefore, long-term sequence monitoring of vegetation in YRB is necessary to show the conservation effect and better support the further protection and restoration. This study analysed vegetation changes from 2000 to 2019 based on an annual mean fractional vegetation cover (FVC) dataset. The Theil-Sen median trend analysis method was used to analyse trends in FVC. The results showed that the vegetation in the YRB has improved significantly, with an average annual growth rate of $0.65 \%$, and the 'green line' of vegetation has moved approximately $300 \mathrm{~km}$ westward. The influence of climate on vegetation is essential; therefore, this study also analysed the influence of temperature and precipitation on vegetation over time and space. Ecological control and afforestation are important anthropogenic factors that affect vegetation. The growth trend $(0.6 \% / a)$ in key ecological function regions (KEFRs) was the fastest, and even though the protection measures are not strict, they provide space for afforestation. The China Ecological Conservation Red Line (CECRL) and the national nature reserves (NNRs) showed relatively flat trends. Ecological afforestation projects were closely correlated with the growth trend of the FVC. The correlation between FVC and the intensity of ecological engineering was significant in typical areas.
\end{abstract}

Keywords: Yellow River Basin; fractional vegetation cover; climate; ecological management; ecological afforestation

\section{Introduction}

Vegetation is a community of plants and the land cover they provide. It plays an important role in the exchange of material and energy on the Earth's surface by maintaining a global ecological balance and promoting atmospheric circulation [1]. The temporal and spatial distribution of vegetation is the basis of environmental science, global change detection, and resource management [2]. It is imperative for the terrestrial circulation system, and provides important ecological and social services for human beings, including net primary production, carbon sources and sinks, climate regulation, water conservation, and biodiversity conservation [3]. The study of vegetation change is an interesting topic for international scholars [4-6]. Fractional vegetation cover (FVC) refers to the percentage of the vertical projection area of vegetation (including leaves, stems and branches) on the ground to the total area of the statistical area, and it is an important global indicator used to assess land cover change, land use, landscapes, and ecosystem functions [7]. It is an important quantitative parameter used to investigate the spatiotemporal state and 
function of terrestrial ecosystems, as well as monitor vegetation changes and evaluate regional environmental quality $[8,9]$. FVC has been widely used in agriculture, soil erosion risk assessment, drought monitoring, environmental assessment, and other fields [10-15]. Remote sensing is the most efficient way to monitor regional and global FVC [16]. It offers a promising alternative to vegetation indices that are currently being used, as it does not relate simply to canopy characteristics [17].

The Yellow River Basin (YRB) flows through four deserts and drought has a serious impact on it. Droughts are a serious issue in river basins of China due to soil and water loss in this fragile environment. The YRB region is key in terms of soil and water conservation in China [18]. Vegetation plays an important role in the ecological development of basins [19]. Due to the dual effects of the harsh natural ecological environment and longterm disorderly human activities, the vegetation in the YRB has been seriously damaged over the last century, and the grassland in the upper Yellow River has degenerated to some extent [20]. Grazing has led to changes in vegetation structure, which has impacted the ecosystem functioning [21-23]. Soil erosion has aggravated in the middle reaches, causing a variety of ecological and environmental problems [24]. Since the 1950s, large-scale ecological restoration projects have been launched to improve the deteriorating ecological environment [25,26], including the Grain-for-Green (GFG) project, Green Wall of China (GWC), and Natural Forest Protection (NFP) project [27]. With the implementation of the GFG, the distribution of water and heat across the region has experienced significant changes [28]. Furthermore, protection systems are continually improving, including the establishment of nature reserves, key ecological function regions, the creation of the China Ecological Conservation Red Line (CECRL), other types of protection areas, and multi-level control gradient difference management, which has laid a solid foundation for vegetation restoration and reconstruction since the 21st century; it continues to play an important role in improving the ecological environment $[29,30]$.

Significant vegetation changes have taken place in the Loess Plateau in recent years [31]. Vegetation changes are closely related to land cover and climate change [32]. Land cover affects the Earth's surface temperature by changing the surface energy balance and microclimate of the region [33]. Liu et al. [34] concluded that the FVC in the Loess Plateau showed an increasing trend from 2000 to 2009, and that temperature, precipitation, and GFG were the main reasons for this change. In the arid and semi-arid regions of north-central YRB, vegetation change trends are significantly positively correlated with temperature and precipitation [35]. Vegetation trends in semi-arid region ecosystems are significantly correlated with precipitation and temperature [36-38]. In the context of climate change, the Loess Plateau will become more humid and warmer from 2001 to 2050 [39]. Vegetation growth will be enhanced and the FVC will expand to new areas [40].

At present, ecological protection and high-quality development of the YRB is a major national strategy. The sustainable development of agriculture, forestry, and animal husbandry in the context of global climate change is key for the high-quality development of the YRB [41]. The dominant influence of human activities on vegetation in the YRB is still reflected in ecological projects, such as the GFG [42]. The Sanjiangyuan and Kubuqi deserts are important areas of ecological engineering [43]. Research has shown that human factors have a greater impact on vegetation cover change than climate change in the YRB [44]. Satellite data showed that China alone accounts for $25 \%$ of the global net increase in leaf area, with only $6.6 \%$ of the global vegetated area in $2000-2017$, and that forests $(42 \%)$ and croplands (32\%) were the main contributors [45].

Vegetation growth has an important effect on the ecological environment. The YRB is a key area to focus on increasing vegetation and it is an important ecological barrier in China. As one of the most important and fragile ecological areas in China, the ecological status of vegetation is seriously threatened. Some areas face ecological problems, such as biodiversity reduction, soil erosion, productivity loss, and declines in service functions [46]. Therefore, it is necessary to carry out long-term sequence monitoring of vegetation changes in the YRB. Remote sensing data are advantageous because of their wide coverage and rapid 
extraction of vegetation information, and can be used in large-scale vegetation dynamic monitoring [47]. Based on long-term series of FVC data in the YRB from 2000 to 2019, this study analysed changes in FVC trends, the regional contribution, changing stability of FVC, as well as the main influencing factors such as climate, ecological management, and ecological engineering. These were analysed at various multi-spatial scales including watershed, control areas, and in typical case areas. This study provides a foundation for the formulation of ecological protection and restoration policies for the YRB.

\section{Materials and Methods}

\subsection{Research Area}

The Yellow River, China's second largest river, originates in the Tibetan Plateau and flows through the Tengger, Ulanbuhe, Kubuqi, and the Mu Us deserts, as well as the Loess Plateau, Hetao Plain, and the North China Plain. The basin covers nine provinces, namely Qinghai, Sichuan, Gansu, Ningxia, Inner Mongolia, Shaanxi, Shanxi, Henan, and Shandong. The annual precipitation in the YRB ranges between $200-700 \mathrm{~mm}$. The climate in the YRB is categorised into four types: humid, semi-humid, semi-arid, and arid. The towns of Hekou and Huayuankou divide the YRB into upstream, midstream, and downstream areas(Figure 1).

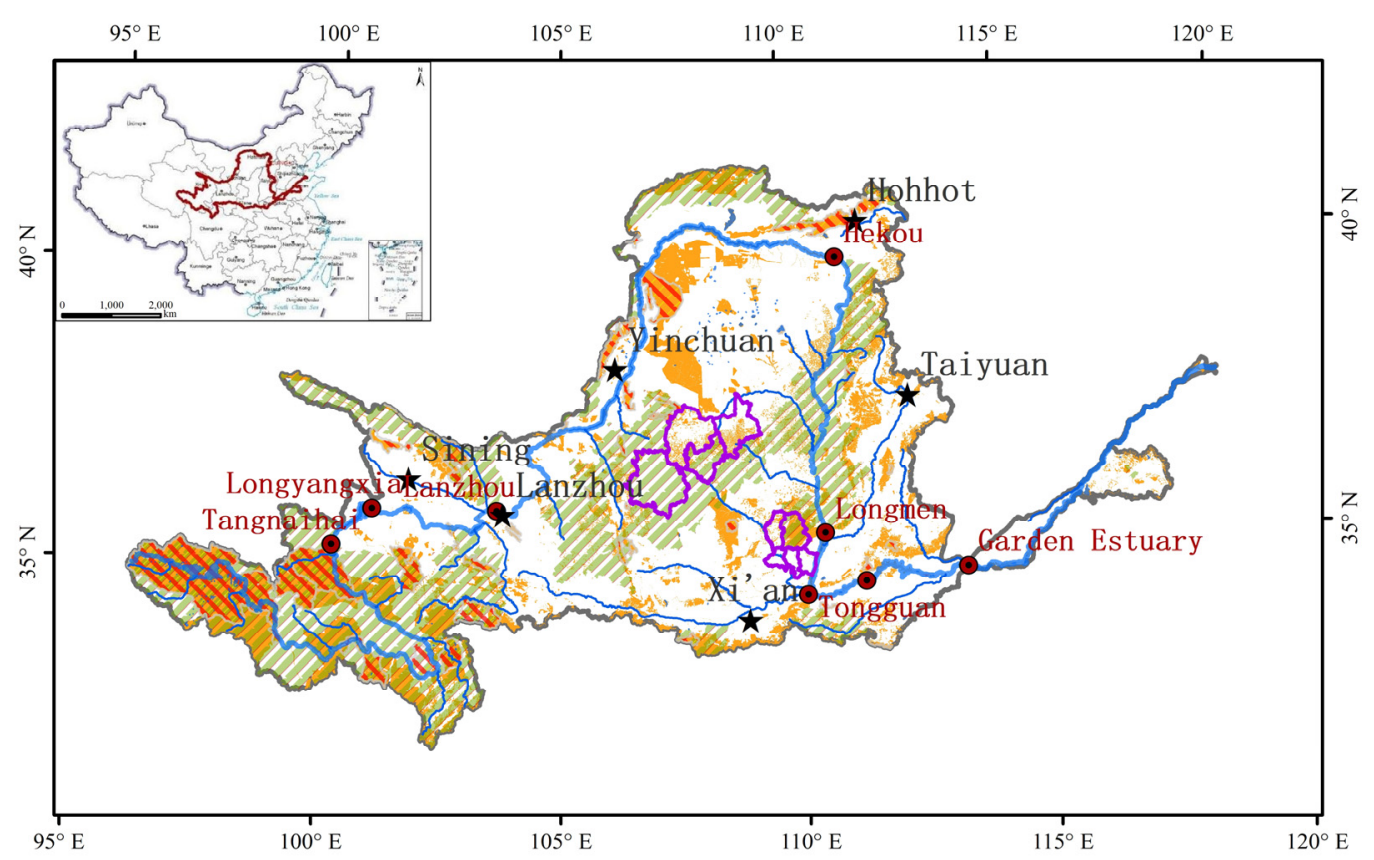

Figure 1. The areas of interest in the YRB mainly include national nature reserves (NNR), China Ecological Conservation Red Lind (CECRL), key ecological function regions (KEFR) and the typical areas.

\subsection{Data Resource}

FVC was calculated from using a MODIS (Moderate-resolution Imaging Spectroradiometer, MODIS) land surface reflectance product. The data had spatial and temporal resolutions of $500 \mathrm{~m}$ and 8 days, respectively. The data required processing and a series of calculations prior to its use in this study. The MODIS product can detect clouds, snow, water, and shadows in fine-grained resolution [48]. A locally adjusted cubic-spline capping method was developed to screen the affected data points at the pixel scale and replace them through temporal interpolation [49]. This algorithm is superior to other similar algorithms in terms of considering the vegetation growth trajectory, protection of key points, noise resistance, and curve stability [50]. FVC data were calculated using a multidimensional lookup table. The annual FVC was calculated from the mean of 46 periods throughout each year. 
Land use data were based on the Ministry of Ecological Environment's 2015-2020 remote sensing investigation and evaluation of the ecological status and changes in China [51]. The FVC vegetation spatial region was extracted from forests, shrubs, grasslands, and croplands. The temperature has a spatial resolution of 0.1 arc degree and can be obtained from NASA's FLDAS dataset [52]. Annual temperature was calculated using monthly temperature data. Precipitation data were obtained from the TerraClimate dataset, with a spatial resolution of 2.5 arc minutes [53]. Annual precipitation was calculated using the monthly precipitation data. The afforestation project data was from the "China Forestry and Grassland Statistical Yearbook," and comprised data from the Grain-for-Green (GFG) project, Green Wall of China (GWC), and Natural Forest Protection (NFP) project, as well as data from local governments, enterprises, and other social afforestation projects.

\subsection{Method}

This study analysed the FVC spatial distribution characteristics and annual variation characteristics. The trend analysis method was used to examine changes in the FVC vegetation area of the YRB by long-term sequencing, as illustrated in Figure 2. These results were divided into five categories: significant increase, slight increase, stable, slight decrease, and significant decrease. In addition, the coefficient of variation indicates the stability of the changes, both temporal and spatial, which is an important indicator used to evaluate the ecological status. The contribution degree indicates the contribution of vegetation changes in a certain region relative to vegetation changes in the whole basin.

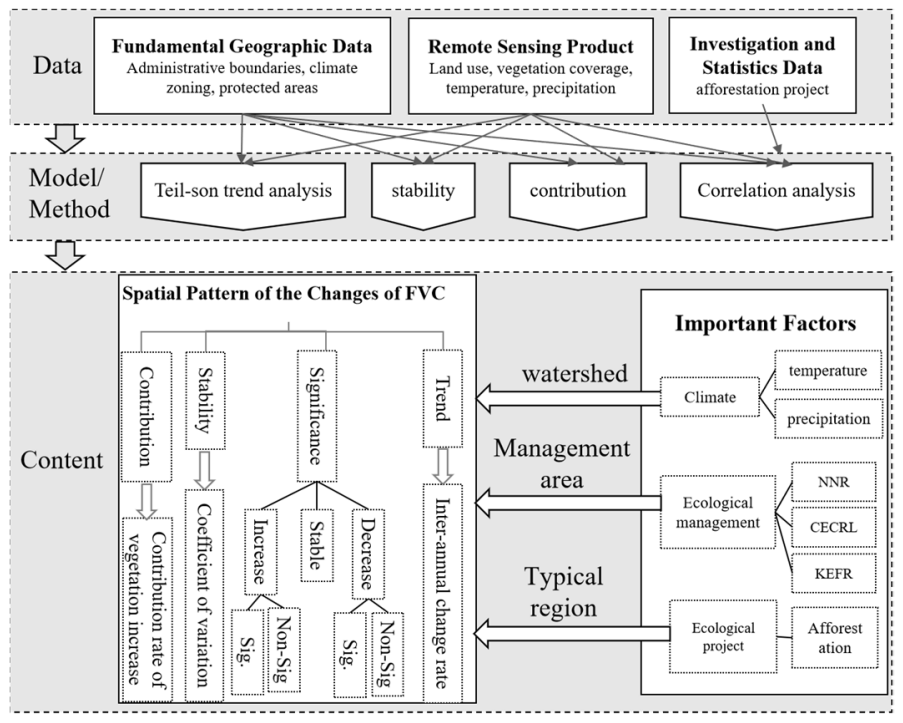

Figure 2. This paper used fundamental geographic data to analyze the boundary of administrative, climate, protected management, etc., which were used generally. Remote sensing products were the main data used to analyze the trends, stability, contributes, and correlation. Investigation and statistics data was to analyzed the correlation of FVC and afforestation project. The main content of this study is to analyze the vegetation change in the YRB from the four aspects of contribution, stability, significance and trend. The influencing factors were analyzed in terms of the relationship between the whole basin and climate, the impact of the control measures on vegetation from the scale of control areas, and the impact of ecological engineering on vegetation from the scale of typical areas (national nature reserves (NNR), China Ecological Conservation Red Lind (CECRL), ckey ecological function regions (KEFR); sig is the abbreviation of significance).

The Theil-Sen median trend analysis method was used to analyse the trend of changes in FVC in the YRB at the pixel scale, which indicates the annual rate of FVC. The MannKendall monotonic trend test was performed to detect trends in the annual FVC average timeseries [54]. This is a non-parametric method, it does not require that the data meet specific criteria (e.g., normal distribution), and also deal with skewed data. Two parameters 
were considered: the correlation coefficient and the significance. The significance values highlight the significance of the trend in slope. In this study, a trend with a $\mathrm{p}$ value of less than 0.05 was considered significant. This method has been widely used in timeseries analyses of hydrology and meteorology. In recent years, this method has been increasingly applied to remote sensing monitoring with the development of remote sensing parameters for timeseries [55-58].

The contribution degree describes the contribution of a certain area to the increase in vegetation across the entire basin over a specific time range. The percentage of FVC for a particular region over the total vegetation is considered to be the variable for the basin:

$$
C=\frac{\sigma_{F V C_{i}}}{\sum_{i=1}^{n} \sigma_{F V C_{i}}}
$$

In the formula, $C$ refers to the contribution of a certain area or surface vegetation type; $\sigma_{F V C_{i}}$ refers to the increment of $F V C$ in the $i$ region or surface vegetation type; $\sum_{i=1}^{n} \sigma_{F V C_{i}}$ refers to the increment of $F V C$ in the YRB.

To evaluate the stability of FVC change from 2000 to 2019, the coefficient of variation (CV) of each pixel was calculated which described the intensity of the inter-annual variation in the vegetation. The formula is as follows:

$$
C V_{F V C}=\frac{\sigma_{F V C}}{F V C}
$$

In the formula, $C V_{F V C}$ is the coefficient of variation of FVC; $\sigma_{F V C}$ is standard deviation of pixels; $F V C$ value is the mean value of the pixel's long time series. The variation coefficient of FVC from 2000 to 2019 was calculated for each pixel and used to analyse the stability of FVC in the timeseries. The larger the value, the more discrete the data distribution between the years, and large fluctuations in the timeseries data resulted in an unstable timeseries. Conversely, smaller values show that the data distribution for each year is relatively stable.

This study calculated the intensity of ecological engineering (IEE) which indicates the unit implementation intensity of the ecological afforestation project in ecological space at county scale. The Pearson correlation coefficient was used to analyse the correlation between FVC changes and the intensity of ecological engineering implementation. The significance level of the correlation was tested according to the table of the critical value of the $t$ distribution. The implementation of ecological engineering has a cumulative effect on the FVC. Therefore, this study compares and examines the correlation between implementation intensity of cumulative engineering and FVC:

$$
\mathrm{IEE}=\mathrm{A} / \mathrm{AES} \times 100 \%
$$

In the formula, IEE is the intensity of the ecological engineering; A is the area of ecological engineering; and AES is the area of ecological space in regional.

Precipitation and temperature influence the FVC. The partial correlation analysis method can reveal whether there is a correlation between the two variables with FVC, without considering other factors. A t-test was performed to determine the significance of the correlation.

National Nature Reserves (NNR), National Key Ecological Function Areas (NKEFA), and Ecological Protection Red Line (EPRL) have different ecological management measures. This study discusses the changing trends in FVC by different management measures and evaluates the results of vegetation protection in different regions.

\section{Results}

\subsection{Spatiotemporal Distribution and Changes in FVC}

The vegetation in the YRB mainly consists of forests, shrubs, grasslands, and croplands. FVC was used to monitor the evolution of vegetation in the YRB. The results showed that 
the FVC in the YRB had a growth trend from 2000 to 2019, and the vegetation 'green line' in the YRB moved westward. The stability showed that the spatial differentiation was affected by climate and other conditions. The contribution degree was used to analyse which interval values contributed the most to the FVC in the watershed.

\subsubsection{FVC Trends and Characteristics}

Over the past 20 years, FVC in the YRB has showed an increasing trend (Figure 3), from $24.05 \%$ to $38.84 \%$. FVC increased rapidly between $2000-2004$, with a $5.67 \%$ increase over five years, accounting for about one-third of the total increase over the past 20 years. This period coincides with the early stage of the GFG project in China, which provided a good foundation for the growth of FVC in the YRB. The spatiotemporal distribution of FVC (Figure 4), the 'green line' (FVC 20\% threshold line), moved westward annually, and gradually moved from semi-humid region to the semi-arid region. The region where the 'green line' moved is mainly located at the border zones of Inner Mongolia, Shaanxi, and Shanxi provinces.

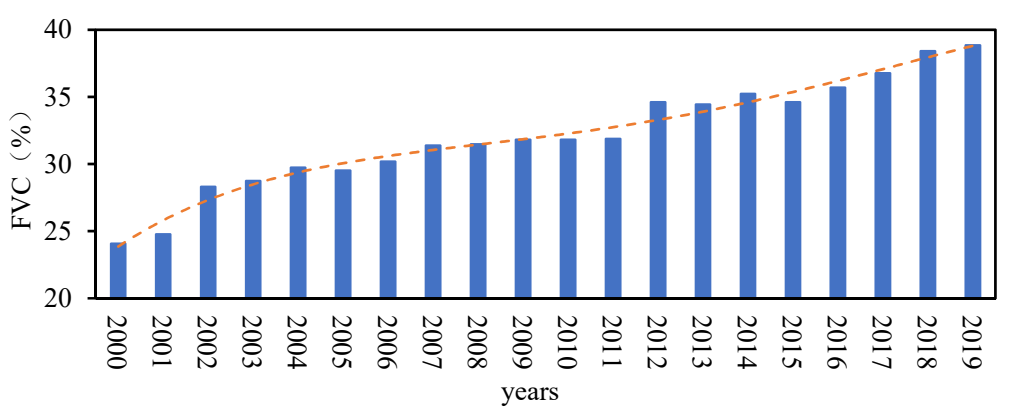

Figure 3. The annual value of FVC in YRB from 2000 to 2019.

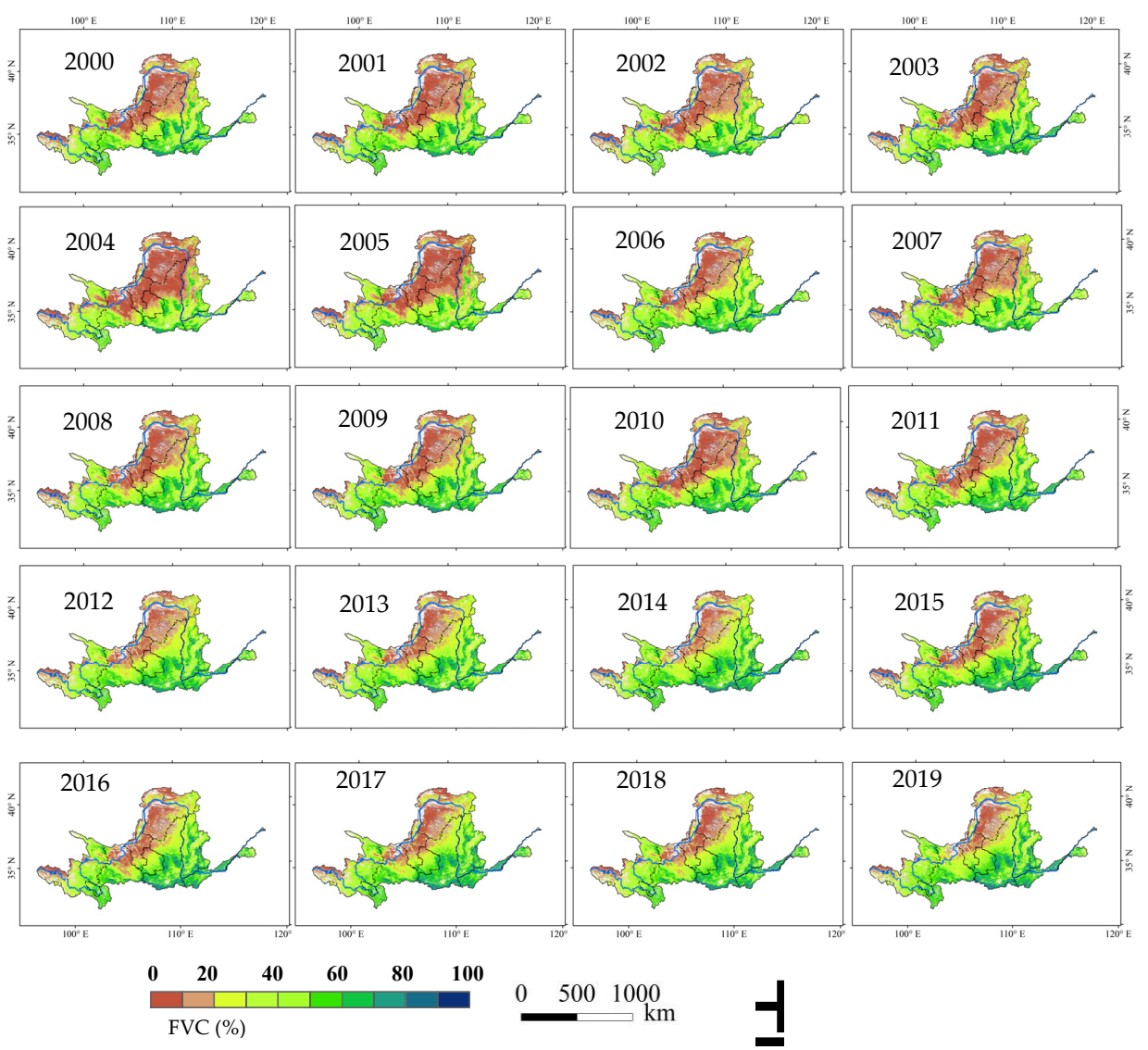

Figure 4. FVC distribution map of the YRB from 2000-2019. 
Analysis of the trend and significance results (Figure 5) show that the annual growth rate in the YRB over the past 20 years was $0.65 \%$. Approximately $83.48 \%$ of the region showed a significant increasing trend, and approximately $2.54 \%$ of the regional FVC showed a decreasing trend. It indicates that the region where the 'green line' advanced was also the region where FVC rapidly increased in the YRB. Regions in northern Shaanxi, such as Yan'an and Wuqi, were the regions with the fastest increasing FVC, and both of these regions are sites where the first batch of pilot areas for the GFG were planted in China.

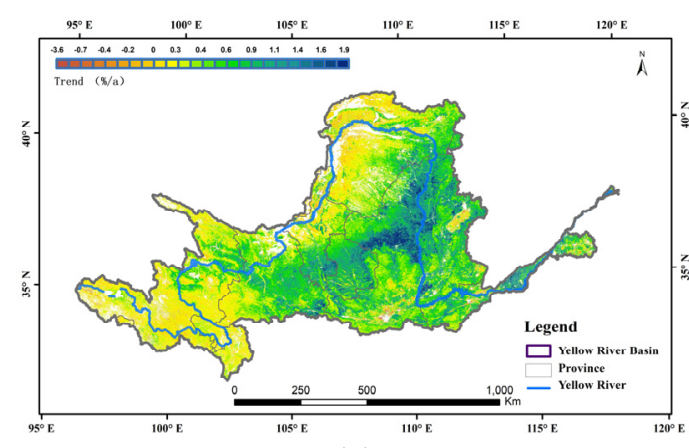

(a)

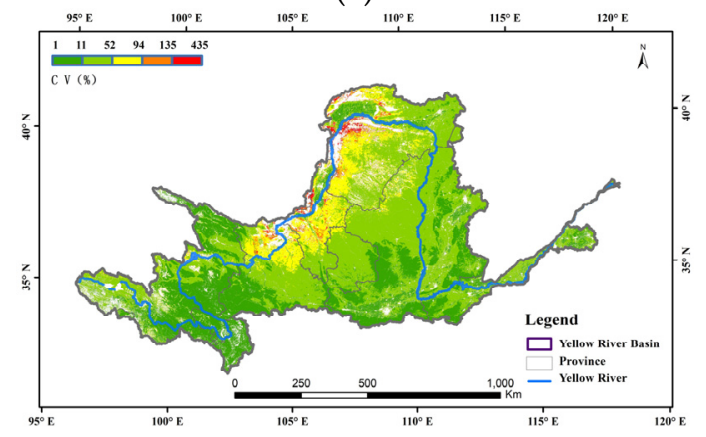

(c)

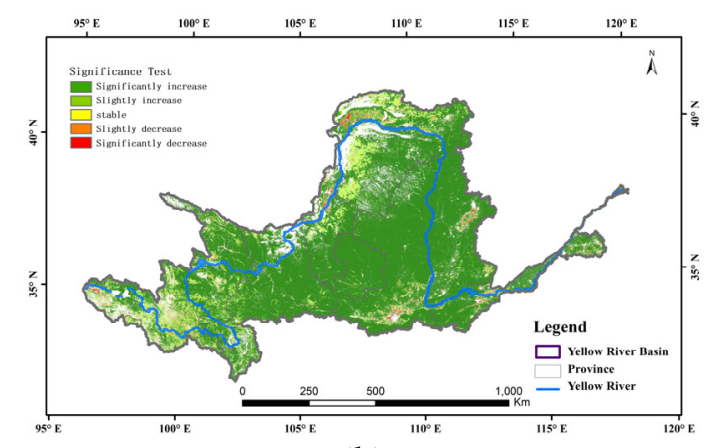

(b)

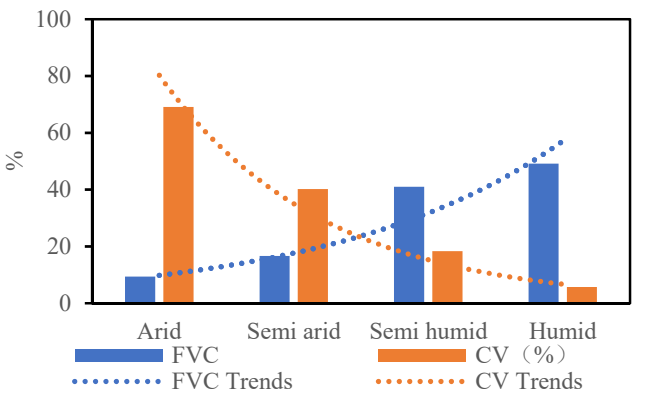

(d)

Figure 5. (a) Trends of FVC between 2000-2019. (b) Significance test of FVC trends. (c) The coefficient of variation (CV) of FVC changes in recent 20 years. (d) The mean and CV of FVC of dry and wet types in recent 20 years.

The spatial distribution of the coefficient of variation showed that FVC stability in the arid and semi-arid areas of northern YRB is poor, but it is good in the semi-humid and humid areas. The CVs in the arid and semi-arid areas were $69.04 \%$ and $40.15 \%$, respectively. The FVC in this region was low, and vegetation was greatly affected by interannual climate fluctuations. The CVs in the semi-humid and humid regions were $18.31 \%$ and 5.67\%, respectively; and were located in southern and southwestern China, respectively. This indicates that the vegetation stability in this region is good. The annual growth rate was $0.80 \%$ in the semi-humid area, which is the fastest in the study area, with a $71.25 \%$ contribution to the basin-wide value and the CV was $18.31 \%$. The CV in the semi-humid area was higher than that in the humid area, and this was mainly due to the continuous growth of vegetation.

\subsubsection{The Contribution of Vegetation}

Vegetation growth is an important aspect of ecological protection. From 2000-2019, vegetation growth rates in different regions were inconsistent with the hydrothermal conditions and human factors. Therefore, the analysis of different vegetation types and FVC ranges are of significance for ecological restoration in the YRB. This study used the equidistant grouping method to divide the FVC into 10 equidistant grades to analyse the changes in FVC at different intervals. The statistical results showed that the FVC mainly changed from $0-20 \%$ to $50-80 \%$. The FVC area between $0-20 \%$ dropped by about 203.4 thousand square kilometres, and the FVC area between $50 \%$ and $80 \%$ increased by approximately 101.0 thousand square kilometres. Vegetation improved significantly in the 
low-FVC areas in 2000. By 2019, the area of high FVC gradually increased, and the area of the low FVC was greatly reduced (Figure 6).

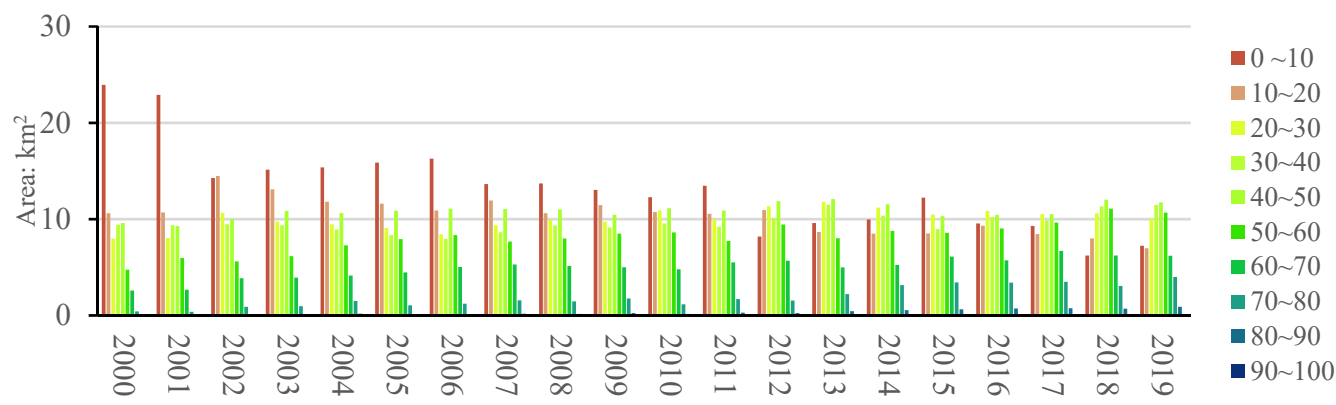

Figure 6. Area changes of different levels of FVC in YRB between 2000-2019.

According to the contribution of each interval to the vegetation increase, regions with higher contributions to the vegetation increase were regions which originally had low FVC. In 2019 , the contribution of FVC in the range of $20-60 \%$ was $68.90 \%$. The region with the highest contribution had an FVC value of $30-40 \%$. In 2000, the regions with the greatest contribution had FVC values between $0 \%$ and $10 \%$, and a contribution of $35.13 \%$ (Figure 7).

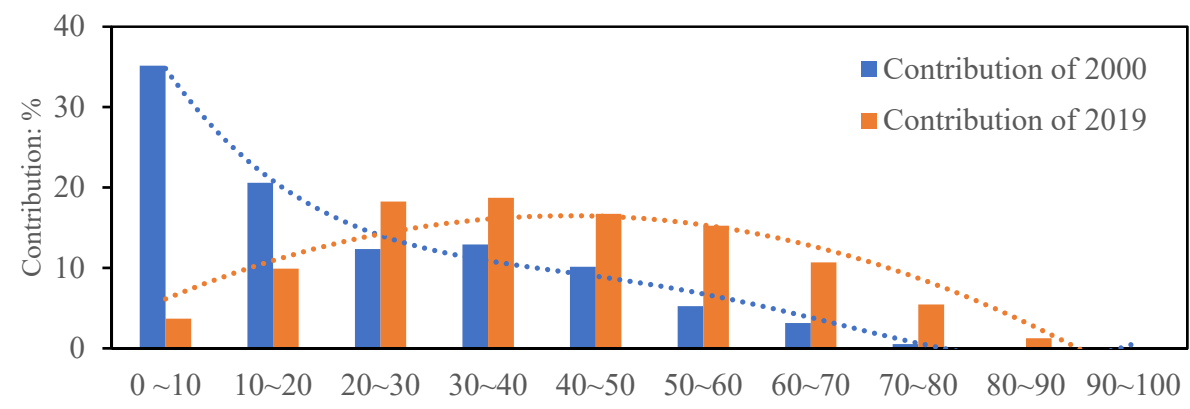

Figure 7. Contribution of different grades of FVC in YRB of 2000 and 2019.

From the statistical results of the vegetation types, grassland has an advantage in terms of its proportional area and contribution to the vegetation increase in the YRB; its FVC value was concentrated in the range of $0-60 \%$ (Figure $8 \mathrm{c}$ ). The grassland area accounts for approximately $41.35 \%$ of the basin area (Figure $8 \mathrm{a}$ ), and the contribution to the basin vegetation was as high as $44.67 \%$ (Figure $8 \mathrm{~b}$ ). The annual growth rate was $0.58 \%$. The second largest contributor was cropland. The proportion of cropland area in the YRB was $19.40 \%$, which is higher than the national average in the Remote Sensing Survey and Assessment of National Decade Change of Ecological Environment (2000-2010) [49]. The FVC was concentrated between $20-50 \%$ (Figure $8 \mathrm{c}$ ), which was higher than the average grassland value. The annual growth rate was the fastest at $0.76 \%$ and its contribution was $32.23 \%$ (Figure 8 b). The FVC of shrubs was mainly distributed between $30-80 \%$, and the forest was mainly distributed between $50-90 \%$ (Figure $8 \mathrm{c}$ ). The contributions of shrubs and forests were $14.73 \%$ and $8.36 \%$, respectively (Figure $8 \mathrm{~b}$ ). In summary, the contribution of grassland and cropland to the increase in FVC in the YRB was high and was mainly located in low FVC areas. Grassland and cropland have advantages in terms of their vegetation type, and their FVC is mostly less than $60 \%$. Forest and shrub FVCs were mostly higher than $70 \%$. The area distribution of the four vegetation types was relatively uniform and in the range of $60-70 \%$ FVC. 


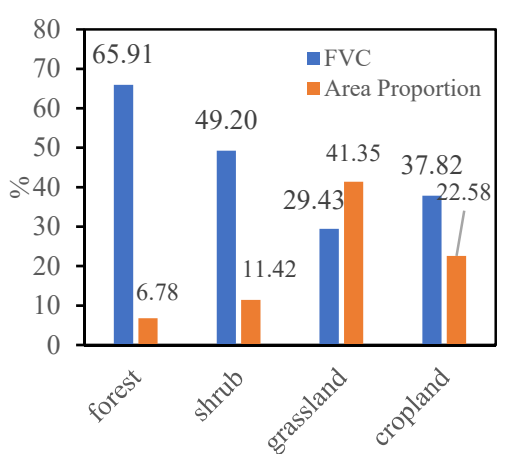

(a)

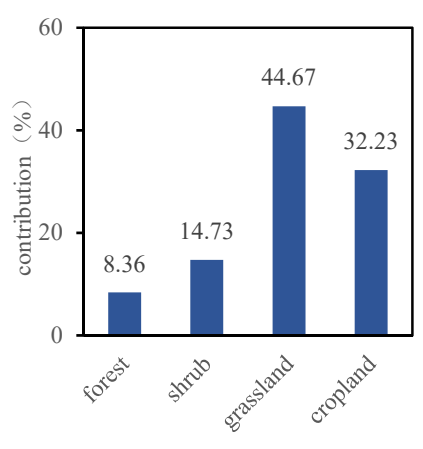

(b)

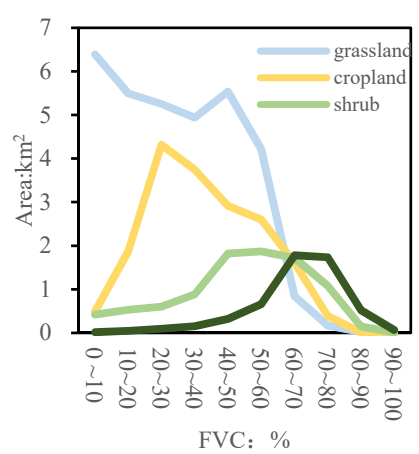

(c)

Figure 8. (a) The FVC and area proportion of different vegetation types. (b) The contribution of different vegetation types. (c) Area proportion of different grades of different vegetation types.

\subsection{Variation Factors}

The FVC types that changed were mainly cropland and grassland in the YRB. The analysis showed that the influence of climate on the FVC was mainly observed spatially, and that temporal changes in the timeseries were not significant. In the arid and semi-arid areas of northern YRB, precipitation had a significant impact on the vegetation coverage, but the correlation was not high and temperature was not found to be significant. Ecological control is an important management mechanism for ecological protection in China. The FVC in the National Key Ecological Function Areas (NKEFA) was the highest, accounting for $39.53 \%$. The FVC in the Ecological Protection Red Line (EPRL) had the fastest growing trend, with an average annual growth rate of $0.6 \%$. Without considering the changes in cropland FVC, the intensity of the ecological afforestation project was highly consistent with an increase in natural vegetation coverage, and the correlation was significant at the 0.01 level.

\subsubsection{Effects of Climatic Factors on Vegetation}

The spatial distribution of climatic factors in the YRB was significantly different. The precipitation gradually decreased from the southeast to the northwest, while the temperature gradually increased. From the watershed point of view, the precipitation in the wetter area in the upper reaches of the YRB showed a slight increasing trend, while there was no obvious trend in the other regions. In terms of the whole basin, the growth in FVC was much higher than the changes in temperature or precipitation (Figure 9a,b). The impact of climate on FVC was mainly reflected spatially, while the change over time was not significant. In the arid and semi-arid areas of northern YRB, precipitation had a significant impact on FVC, but not on their correlation. The correlation between temperature and FVC was not significant (Figure 9c, Table 1). The main vegetation ecosystem type in northern Shaanxi, southwestern Inner Mongolia, and northern Ningxia was cropland, which was characterized by high temperature, lower amount of precipitation, and large amount of evaporation. The partial correlation between precipitation and vegetation was relatively strong.

From the spatial distribution perspective (Figure 10), the partial correlation between FVC and precipitation was relatively strong in the whole basin, except for in the southeast. The partial correlation between precipitation and FVC was the strongest in the northwest region. Regions with a high partial correlation with temperature were mainly located in the eastern and western YRB, while the partial correlation between Ningxia, eastern Gansu, and southern Shaanxi was weak. 


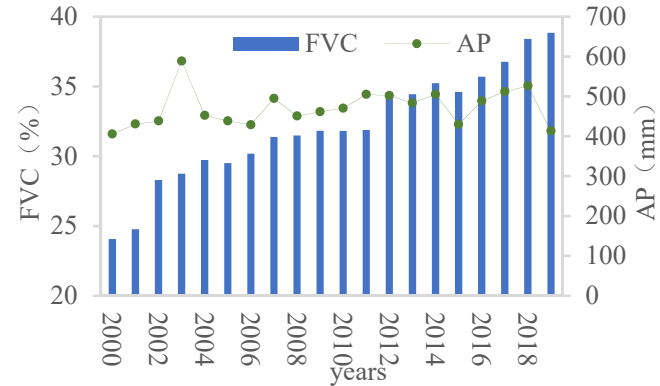

(a)
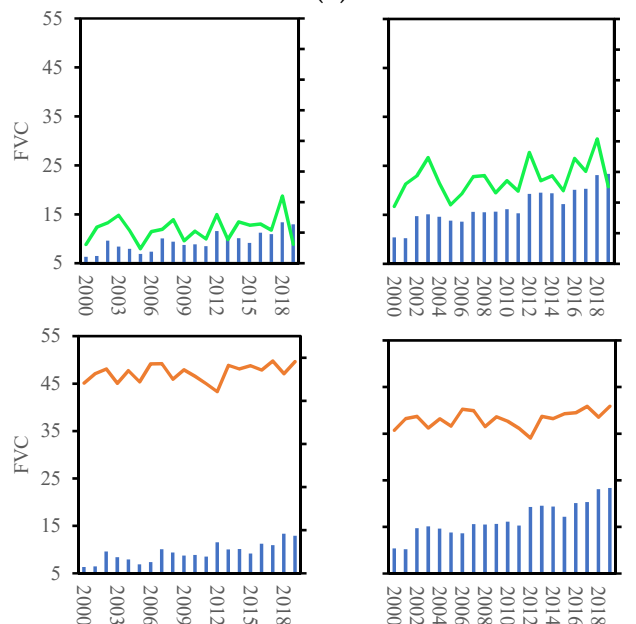

Arid, semi-arid, semi humid, humid

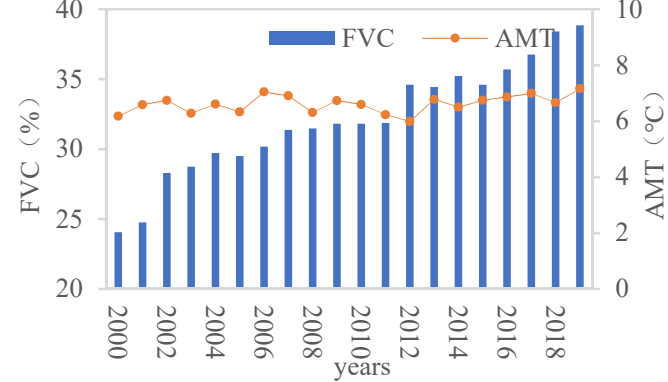

(b)
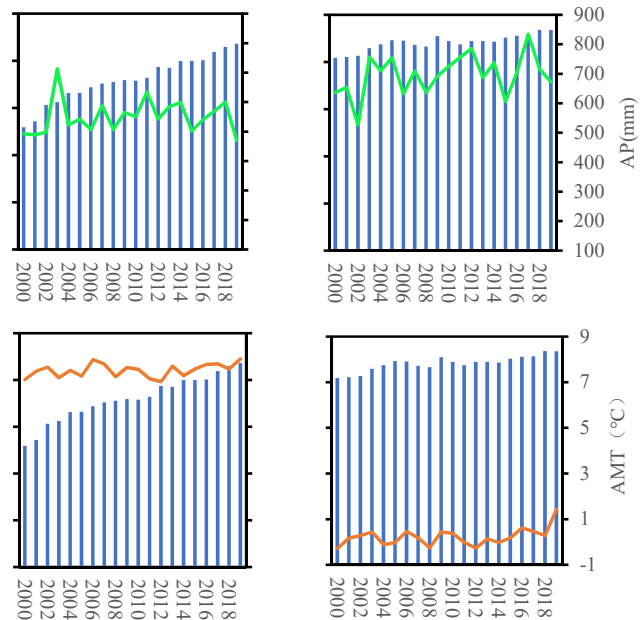

FVC Precipita- Temperature

(c)

Figure 9. (a) The trends of FVC and precipitation changes in 20 years. (b) The trends of FVC and temperature changes in 20 years. (c) The correlation of precipitation and temperature with FVC in different climate regions. (The AP is the abbreviation of annual precipitation. ATP is the abbreviation of annual average temperature).

Table 1. The partial correlation of precipitation and temperature with FVC.

\begin{tabular}{cccccc}
\hline \multirow{2}{*}{ Partial Correlation Analysis } & & \multicolumn{3}{c}{ Fractional Vegetation Cover (FVC) } \\
\cline { 2 - 6 } & PCC & Arid & Semi Arid & Semi Humid & Humid \\
\hline \multirow{2}{*}{ Precipitation } & Partial correlation coefficient & 0.532 & 0.649 & 0.258 & 0.504 \\
& Significance (bilateral) & 0.019 & 0.003 & 0.25 & 0.028 \\
\cline { 2 - 6 } Temperature & Partial correlation coefficient & 0.387 & 0.47 & 0.445 & 0.586 \\
& Significance (bilateral) & 0.101 & 0.042 & 0.056 & 0.008 \\
\hline
\end{tabular}

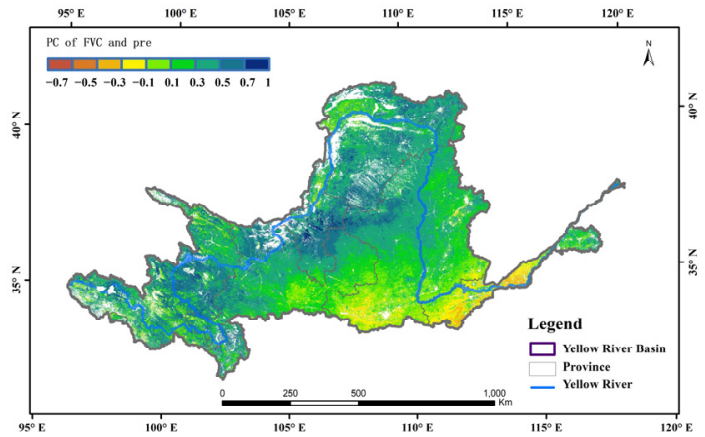

(a)

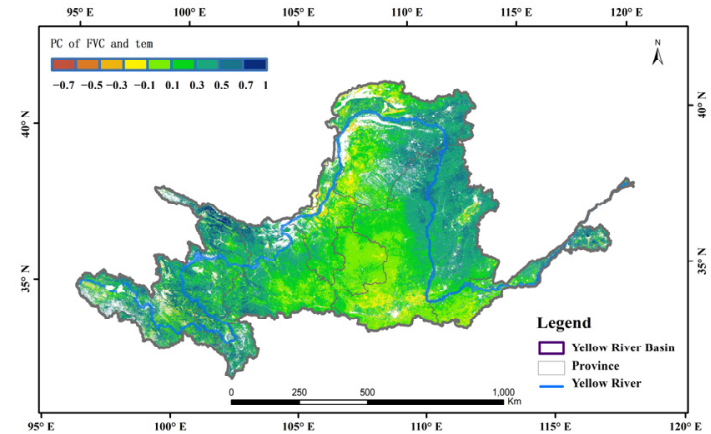

(b)

Figure 10. PC is the partial correlation coefficient. (a) The spatial distribution map of the partial correlation coefficient of FVC with precipitation. (b) The spatial distribution map of the partial correlation coefficient of FVC with temperature. 


\subsubsection{The Relationship between Ecological Management and Vegetation}

While carrying out a large number of ecological projects in the YRB, multi-level ecological management measures were implemented to provide a regional basis for protecting the ecological environment. Among these, national nature reserves (NNRs) and the China Ecological Conservation Red Line (CECRL) are prohibited development zones, while the key ecological function regions (KEFRs) are restricted development zones. These areas provide protection for important ecological resources in China. However, the China Ecological Conservation Red Line (CECRL) was implemented later than the NNR. In 2014, the Former Ministry of Environmental Protection issued the National Ecological Protection Redline-Technical Guidelines for Delineating Baseline of Ecological Functions (Trial) to further perfect the ecological protection system in China [59].

According to different control types, the FVC of CECRL in the YRB during the most recent five years was $39.53 \%$, which was higher than the average level of $36.85 \%$. The FVC values of KEFR and NNR were $36.25 \%$ and $34.36 \%$, respectively. From the perspective of changes in the trends, the growth trend of KEFR was the fastest, with an average annual growth rate of $0.6 \%$, while vegetation stability in the NNR was the best, with an average annual growth rate of $0.31 \%$. Before 2011, the FVC of the NNR was higher than that of the KEFR, after which the key ecological function areas obtained the advantage (Figure 11).

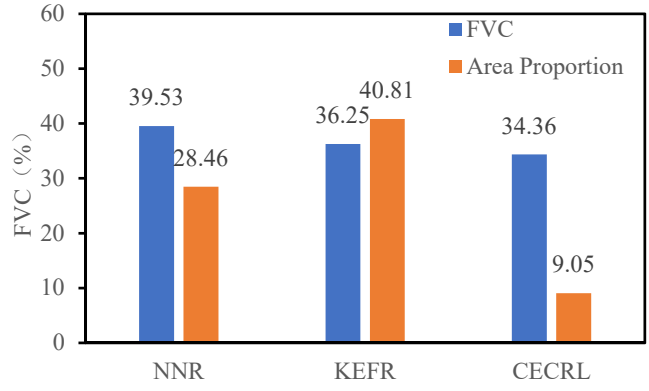

(a)

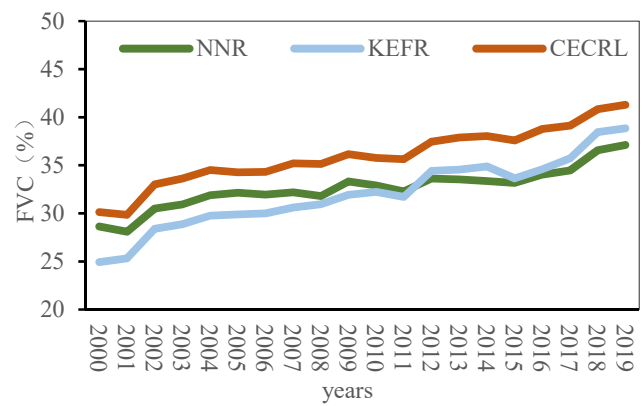

(b)

Figure 11. (a) FVC and the area proportion in different ecological management areas. (b) The changes of FVC in different ecological management areas year by year.

\subsubsection{Effects of Ecological Afforestation on Vegetation}

The YRB is a key area for ecological afforestation projects, so it is necessary to analyse the effects of ecological afforestation projects on the vegetation. Areas with ecological afforestation projects were available at the county level, but the specific locations were difficult to obtain. Therefore, we assumed that the implementation scope of the afforestation projects was the current ecological space. We then calculated the percentage of the afforestation area in ecological space as the intensity of the ecological afforestation projects. Considering the cumulative effect of ecological afforestation, the cumulative area of ecological afforestation over the past 20 years was used to calculate the intensity of ecological afforestation projects. When selecting typical areas, it is important to avoid the influence of climate and natural factors on the vegetation. Therefore, the two typical areas that were chosen are significantly different from the surrounding counties. That is, the growth rates of FVC in Huanglong were higher than those in the surrounding areas, while the growth rates in Wuqi were lower than those in the surroundings areas.

\section{(1) The Typical Area of Huanglong and the Surrounding County}

The FVC in Huanglong County was significantly higher than that of the surrounding countryside, and the FVC was stable over a long time. The FVC in Luochuan County was high, while the intensity of afforestation projects per unit area was relatively small and the growth trend was very large (Figure 12). Studies have shown that the reason for this phenomenon may be due to the county's development with an apple tree economic forest industry [60], which plays an important role in improving the county's FVC. 


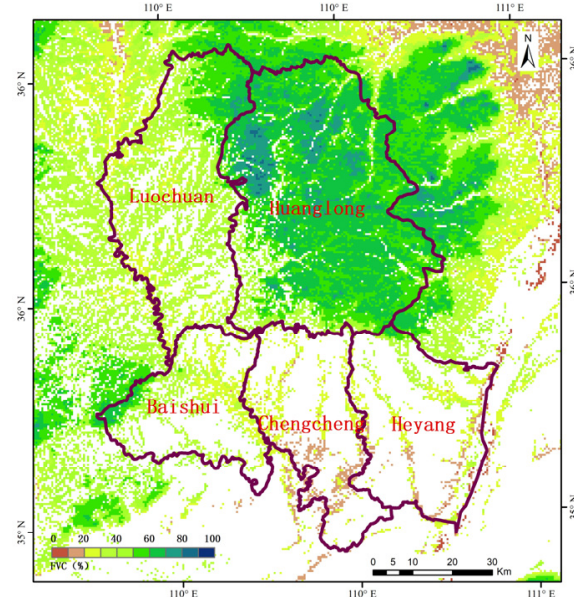

(a)

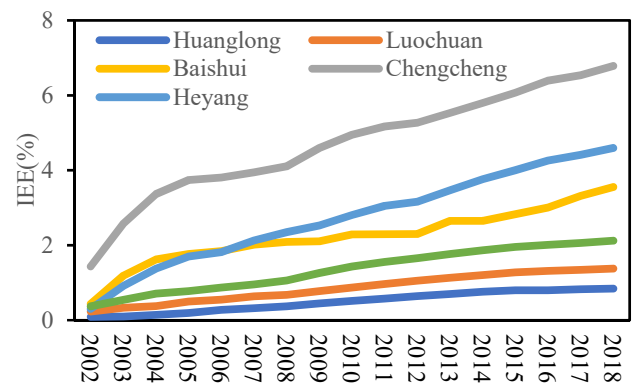

(c)

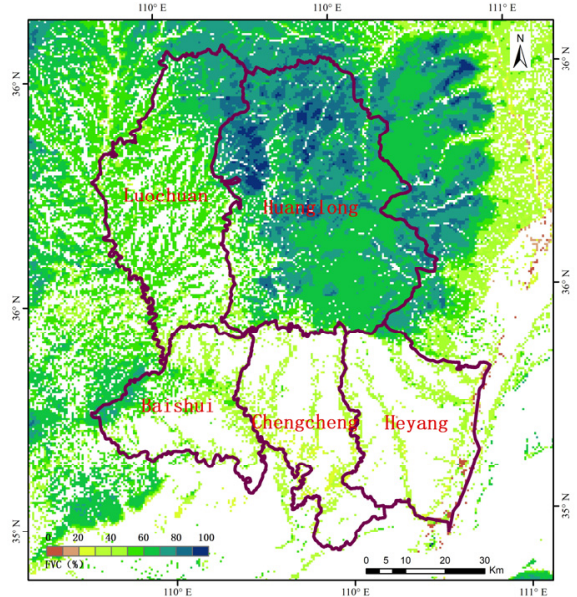

(b)

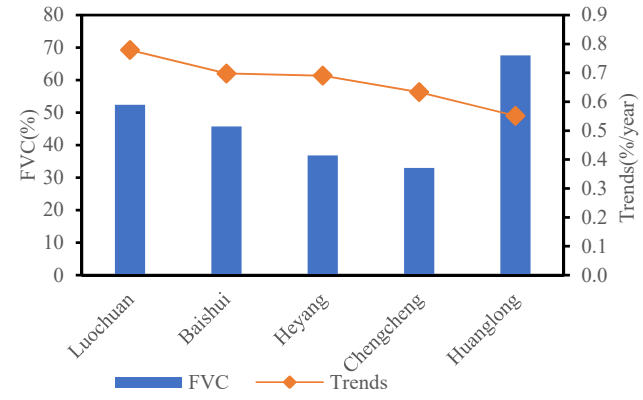

(d)

Figure 12. (a) is the 2000 year and the (b) is the 2019 year of the Spatial distribution of FVC in Huanglong and the typical area of the surrounding county. (c) The intensity of ecological afforestation (IEE) of each county in Huanglong and the surroundings. (d)The FVC and trends of each county in Huanglong and the surroundings.

\section{(2) The Typical Area of Wuqi and the Surrounding County}

The region's typical natural conditions for vegetation growth are fairly poor, and the FVC is generally low. The low amount of precipitation is not conducive for vegetation growth. The results showed that the FVC in 2019 was significantly better than that in 2000. The FVC values and growth trend in Wuqi County were significantly higher than those in the adjacent counties. The afforestation intensity per unit area was high in Wuqi, Jingbian, and Dingbian counties. After 2014, the growth rate of afforestation in Wuqi County was higher than that in other regions, and the FVC growth trend was faster. In contrast, the afforestation intensity in Huanxian County was the lowest, while the growth trend of FVC was insignificant, increasing at an annual rate of $0.92 \%$, which is equivalent to the growth trend in Jingbian County (Figure 13).

Pearson correlation analysis was used to analyse afforestation intensity and FVC values. The results showed that the intensity of ecological afforestation was significantly correlated with an increase in FVC. The correlation coefficients of Luochuan, Wuqi, Jingbian, and Huanglong counties were high at $0.95,0.925,0.896$, and 0.88 , respectively, and were higher than other counties. The correlation coefficients of Chengcheng, Heyang, and Dingbian counties were low (Table 2). The implementation of ecological afforestation plays an important role in promoting the growth of FVC. The rate of FVC growth in each region is affected by the intensity of the afforestation project during implementation, as well as the geography, climate, economics of the forest, and later afforestation maintenance. Huanxian is located at the junction of arid and semi-arid areas, and its vegetation growth potential is low; therefore, it is not suitable to implement an ecological construction mode dominated by trees [61]. Therefore, the simultaneous implementation of grassland restoration projects and the rational allocation of trees, shrubs, and grasses can effectively ensure the survival rate of vegetation and improve the FVC $[62,63]$. Consequently, climate and hydrology in 
different regions has an impact on the success of afforestation. Therefore, it is necessary to formulate scientific plans to improve the effectiveness of vegetation restoration.

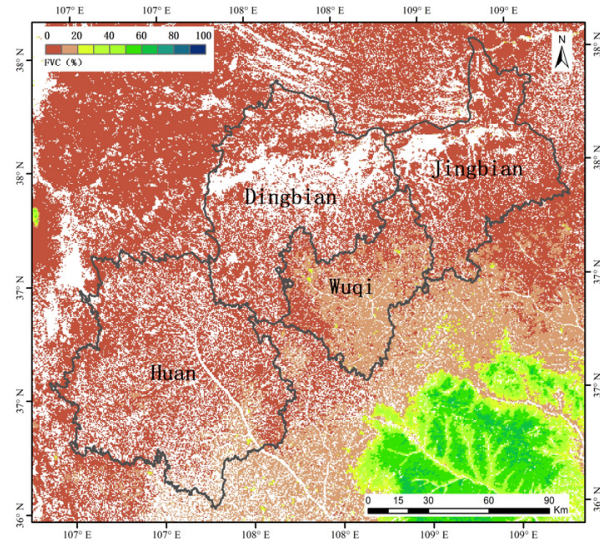

(a)

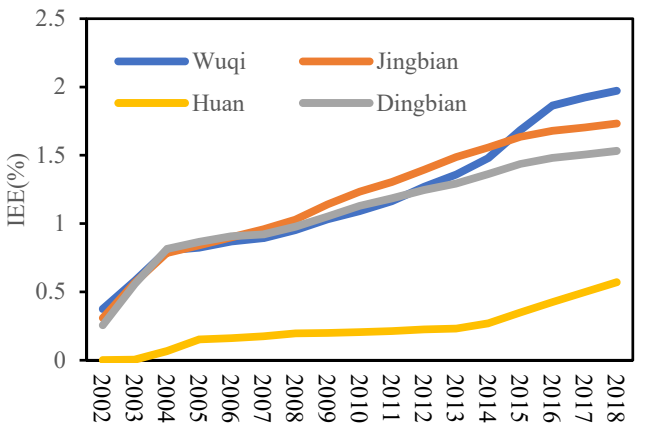

(c)

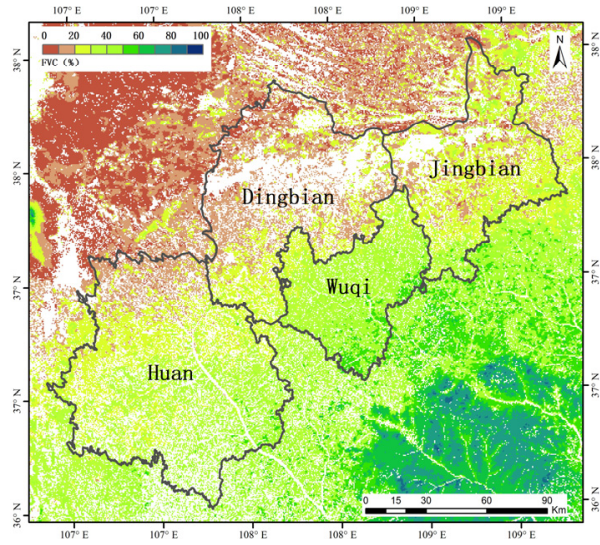

(b)

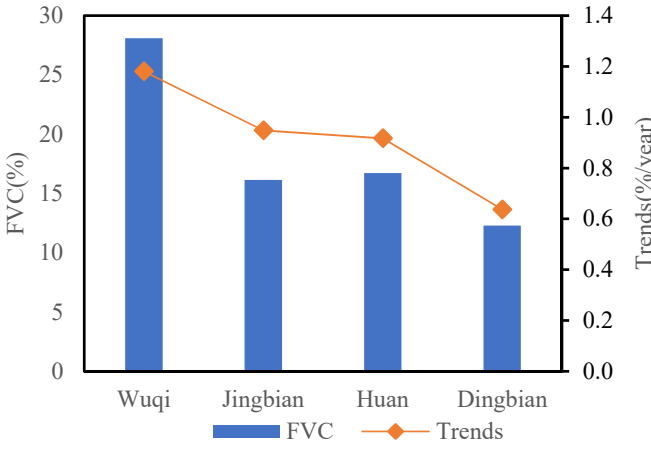

(d)

Figure 13. (a) is the 2000 year and the (b) is the 2019 year of the Spatial distribution of FVC in Wuqi and the surrounding county typical area. (c) The intensity of ecological afforestation (IEE) of each county in Wuqi and the surroundings. (d) The FVC and trends of each county in Wuqi and the surroundings.

Table 2. Correlation between FVC and afforestation engineering intensity in typical areas. * indicates the significance of the correlation test. 0.01 * represents a significant correlation at the 0.01 level. $0.05 *$ represents a significant correlation at the 0.05 level.

\begin{tabular}{cccccc}
\hline County & Pearson Correlation & Significance & County & Pearson Correlation & Significance \\
\hline Huanglong & 0.88 & $0.01^{*}$ & Wuqi & 0.925 & $0.01 *$ \\
Luochuan & 0.95 & $0.01^{*}$ & Jingbian & 0.896 & $0.01^{*}$ \\
Baishui & 0.66 & $0.01^{*}$ & Huan & 0.714 & $0.01 *$ \\
Chengcheng & 0.56 & $0.05^{*}$ & Dingbian & 0.639 & $0.01 *$ \\
Heyang & 0.62 & $0.01^{*}$ & & & \\
\hline
\end{tabular}

\section{Conclusions and Discussion}

This study analysed the spatiotemporal variation and main impact factors of vegetation in the YRB based on the annual average value of FVC from 2000 to 2019. FVC in the YRB showed an increasing trend. The 'green line' of vegetation moved westward by approximately $300 \mathrm{~km}$, advancing from the semi-humid area to the semi-arid area, which is located at the junction zone of Inner Mongolia, Shaanxi, and Shanxi provinces. Grassland and farmland contributed the most to the growth of FVC. Vegetation and the ecological environment of the YRB has gradually improved over the last 20 years.

The regions with FVC values between $0-10 \%$ made the greatest contribution. YRB is an important agricultural area, and the percentage of cropland is higher than the national 
average. The development of modern agriculture contributed to a $32.23 \%$ increase in FVC in the YRB. Grassland is the main vegetation type in low FVC areas, contributing $44.67 \%$ to the vegetation increase. Limited by climatic and water conditions, it is more difficult for FVC in the northwest region of the YRB to reach higher levels. Therefore, more attention should be paid to the effects of vegetation restoration measures. In addition, scientific and appropriate ecological restoration decisions should be considered before implementing ecological afforestation.

Climate is an essential factor that affects the distribution of vegetation. The spatial distribution of vegetation stability was very consistent with the spatial distribution of the climate. This study analysed the partial correlation of FVC with precipitation and temperature in two dimensions, that is, over time and space. The results showed a trend of weak growth in wet areas, while other areas showed no obvious increasing trends in FVC. The interannual fluctuation was more significant than the growth trend. Therefore, it is difficult to explain the correlation between FVC and climatic factors temporally. Spatially, climate correlates with the vegetation distribution, but the correlation is not significant. This may have been caused by the synergistic effects of the two factors. Regions with rapid vegetation growth were mainly located in the middle of the YRB, and there was no significant correlation between climatic factors and vegetation in this region. Human factors may have a greater impact on the growth of vegetation.

The YRB is a key area of ecological protection, and projects such as the NNR, CECRL, and KEFR have been implemented there. The impact of ecological control on vegetation was demonstrated by the growth rate of the FVC. KEFR is a restricted development zone that allows for human activities and ecological engineering. NNR and CECRL are prohibited development zones, which are strictly protected areas that are supplemented by certain ecological restoration measures. The results showed that the growth trend in KEFR was the fastest, while NNR and CECRL showed slower growth trends. This indicates that human factors promote vegetation restoration in the YRB.

Over the last century, a variety of ecological projects have been continuously carried out in the YRB. According to the change in FVC, climatic factors, and ecological control ecological afforestation projects may be closely related to vegetation restoration. By analysing the correlation between the intensity of ecological afforestation and the growth trend of FVC, a high correlation in typical areas was found. In most areas, with more intense ecological afforestation, the faster FVC increased. However, this is not applicable in all areas due to other factors, such as an unsuitable climate, poor water conditions, and large-scale economic forest development. A wider range of data is required to perform this analysis. However, there is no doubt that ecological afforestation projects greatly promote vegetation restoration.

Author Contributions: Conceptualization, P.S., P.H. and J.G.; Methodology, P.S., P.H., H.W. and J.G.; Data Analysis, P.S. and Y.W.; Supervision, P.H., H.W. and J.G.; Visualization, P.S., Y.W. and C.S.; Writing, P.S., P.H. and H.W. All authors have read and agreed to the published version of the manuscript.

Funding: This research was funded by the National Key R\&D Program of China, Grant number 2016YFC0500206, 2017YFC0506506).

Institutional Review Board Statement: Not applicable.

Informed Consent Statement: Not applicable.

Data Availability Statement: The temperature datasets could be obtained from the NASA GES DISC [50]: available at https://disc.sci.gsfc.nasa.gov/datasets?keywords=FLDAS (accessed on 1 June 2020). The precipitation data are come from TerraClimate dataset with the spatial resolution of 2.5 arc minutes [51], available at IDAHO_EPSCOR/TERRACLIMATE (accessed on 1 June 2020). The afforestation project data available at https: / / data.cnki.net/ (accessed on 1 June 2020). The FVC datasets was provided by Institute of Geographic Sciences and Natural Resources Research CAS. 
Acknowledgments: We acknowledge all the institutions and communities that provided free software, R community, and the institutions and communities supplying data (GES DISC, IDAHO_EPSCOR).

Conflicts of Interest: The authors declare no conflict of interest.

\section{References}

1. Xiao, J.F.; Moody, A. A comparison of methods for estimating fractional green vegetation cover within a desert-to-upland transition zone in central New Mexico, USA. Remote Sens. Environ. 2005, 98, 237-250. [CrossRef]

2. Lu, H.; Raupach, M.R.; McVicar, T.R.; Barrett, D.J. Decomposition of vegetation cover into woody and herbaceous components using AVHRR NDVI time series. Remote Sens. Environ. 2003, 86, 1-18. [CrossRef]

3. Ma, H.X.; Chen, C.C.; Song, Y.Q.; Ye, S.; Hu, Y.M. Analysis of vegetation cover change and its driving factors over the past ten years in Qinghai province. Res. Soil Water Conserv. 2018, 25, 137-145. [CrossRef]

4. Liu, B.Z.; Fang, X.Q.; He, Q.S.; Rong, Q.Y. Monitoring the changes of vegetation based on MODIS data and BFAST methods. Remote Sens. Land Resour. 2016, 28, 146-153. [CrossRef]

5. Yang, L.; Jia, K.; Liang, S.; Liu, J.; Wang, X. Comparison of Four Machine earning Methods for Generating the GLASS Fractional Vegetation Cover Product from MODIS Data. Remote Sens. 2016, 8, 682. [CrossRef]

6. Cao, W.; Wu, D.; Huang, L.; Liu, L. Spatial and temporal variations and significance identification of ecosystem services in the Sanjiangyuan National Park, China. Sci. Rep. 2020, 10, 6151. [CrossRef] [PubMed]

7. Hill, J.M.; Guerschman, P.J. The MODIS Global Vegetation Fractional Cover Product 2001-2018: Characteristics of Vegetation Fractional Cover in Grasslands and Savanna Woodlands. Remote Sensing. Remote Sens. 2020, 12, 406. [CrossRef]

8. Ding, Y.; Zheng, X.; Zhao, K.; Xin, X.; Liu, H. Quantifying the Impact of NDVIsoil Determination Methods and NDVIsoil Variability on the Estimation of Fractional Vegetation Cover in Northeast China. Remote Sens. 2016, 8, 29. [CrossRef]

9. Wu, D.H.; Wu, H.; Zhao, X.; Zhou, T.; Tang, B.J.; Zhao, W.Q.; Jia, K. Evaluation of spatiotemporal variations of global fractional vegetation cover based on GIMMS NDVI data from 1982 to 2011. Remote Sens. 2014, 6, 4217-4239. [CrossRef]

10. Zhang, C.S.; Hu, Y.; Shi, X.L. Analysis of spatial-temporal evolution of vegetation cover in Loess Plateau in recent 33 years based on AVHRR NDVI and MODIS NDVI. J. Appl. Sci. Electron. Sand Inf. Eng. 2016, 34, 702-712. [CrossRef]

11. Dong, J.F.; Yuan, Y.; He, H.J.; Gao, B. Analyses of spatial-temporal changes of leaf area index in Shaanxi province based on MODIS. J. Northwest Univ. 2016, 31, 79-85. [CrossRef]

12. Zhang, Y.; Zhang, C.B.; Wang, Z.Q.; An, R.; Li, J.L. Comprehensive Research on Remote Sensing Monitoring of Grassland Degradation: A Case Study in the Three-River Source Region, China. Sustainability 2019, 11, 1845. [CrossRef]

13. Piao, S.L.; Yin, G.D.; Tan, J.G.; Cheng, L.; Huang, M.T.; Li, Y.; Liu, R.G.; Mao, J.F.; Myneni, R.B.; Peng, S.S.; et al. Detection and attribution of vegetation greening trend in China over the last 30 years. Glob. Chang. Biol. 2015, 21, 1601-1609. [CrossRef]

14. Xiao, J.S.; Qiao, B.; Chen, G.Q.; Shi, F.F.; Cao, X.Y.; Zhu, C.X. Land use change and evolution of ecosystem service value in Maduo County of source region of the Yellow River. Acta Ecol. Sin. 2020, 40, 510-521. [CrossRef]

15. Jia, K.; Liang, S.; Gu, X.; Baret, F.; Wei, X.; Wang, X.; Yao, Y.; Yang, L.; Li, Y. Fractional vegetation cover estimation algorithm for Chinese GF-1 wide field view data. Remote Sens. Environ. 2016, 177, 184-191. [CrossRef]

16. Mu, X.H.; Song, W.J.; Gao, Z.; McVicar, T.R.; Donohuec, R.J.; Yan, G.J. Fractional vegetation cover estimation by using multi-angle vegetation index. Remote Sens. Environ. 2018, 216, 44-56. [CrossRef]

17. Bareta, F.; Hagolle, O.; Geiger, B.; Bicheron, P.; Miras, B.; Huc, M.; Berthelot, B.; Niño, F.; Weiss, M.; Samain, O.; et al. LAI, fAPAR and fCover cyclipes global products derived from vegetation Part 1: Principles of the algorithm. Remote Sens. Environ. 2007, 110, 275-286. [CrossRef]

18. Yi, L.; Ren, Z.Y.; Zhang, C.; Liu, W. Vegetation Cover, Climate and Human Activities on the Loess Plateau. Resour. Sci. 2014, 36, $166-174$.

19. Jeong, S.-J.; Ho, C.-H.; Park, T.-W.; Kim, J.; Levis, S. Impact of vegetation feedback on the temperature and its diurnal range over the Northern Hemisphere during summer in a $2 \times \mathrm{CO}_{2}$ climate. Clim. Dyn. 2011, 37, 821-833. [CrossRef]

20. Li, X.; Wang, H.; Fu, N.; Wang, D.; Zhang, L. Estimating vegetation fractional coverage for temperate grassland in northern China based on remotely sensed data and rainfall time series. In Proceedings of the 2007 IEEE International Geoscience and Remote Sensing Symposium, Barcelona, Spain, 23-28 July 2007; IEEE: Piscataway, NJ, USA. [CrossRef]

21. Adler, P.; Raff, D.; Lauenroth, W. The effect of grazing on the spatial heterogeneity of vegetation. Oecologia 2001, 128, 465-479. [CrossRef]

22. Eldridge, D.J.; Poore, A.; Ruiz-Colmenero, M.; Letnic, M.; Soliveres, S. Ecosystem structure, function, and composition in rangelands are negatively affected by livestock grazing. Ecol. Appl. 2016, 26, 1273-1283. [CrossRef]

23. Gaitán, J.J.; Bran, D.; Oliva, G.E.; Aguiar, M.R.; Buono, G.G.; Ferrante, D.; Nakamatsu, V.; Ciari, G.; Salomone, J.M.; Massara, V.; et al. Aridity and Overgrazing Have Convergent Effects on Ecosystem Structure and Functioning in Patagonian Rangelands. Land Degrad. Dev. 2018, 29, 210-218. [CrossRef]

24. Li, W.; Zhao, J.; Pan, J.H.; Li, X. A Research of Net Primary Productivity Model of Grassland Based on MODIS Data in the Loess Plateau of China. Remote Sens. Technol. Appl. 2009, 24, 660-664.

25. Liang, W.; Bai, D.; Wang, F.Y.; Fu, B.J.; Yan, J.P.; Wang, S.; Yang, Y.T.; Long, D.; Feng, M.Q. Quantifying the impacts of climate change and ecological restoration on streamflow changes based on a Budyko hydrological model in China's Loess Plateau. Water Resour. Res. 2015, 51, 6500-6519. [CrossRef] 
26. Xiao, J.F. Satellite evidence for significant biophysical consequences of the "Grain for Green" Program on the Loess Plateau in China. J. Geophys. Res. Biogeosci. 2014, 119, 2261-2275. [CrossRef]

27. Lu, Y.H.; Zhang, L.W.; Feng, X.M.; Zeng, Y.; Fu, B.J.; Yao, X.L.; Li, J.R.; Wu, B.F. Recent ecological transitions in China-greening, browning, and influential factors. Sci. Rep. 2015, 5, 8732. [CrossRef]

28. Liu, Y.; Fu, B.J. Topographical variation of vegetation cover evolution and the impact of land use/cover change in the Loess Plateau. Arid. Land Geogr. 2013, 36, 1097-1102. [CrossRef]

29. Jin, Z.; Liang, W.; Yang, Y.T. Separating Vegetation Greening and Climate Change Controls on Evapotranspiration trend over the Loess Plateau. Sci. Rep. 2017, 7, 1-15. [CrossRef]

30. Wen, Z.M.; Feng, J. Review of the studies on the prediction of natural vegetation distribution. Sci. Soil Water Conserv. 2009, 7, 117-124. [CrossRef]

31. Wohlfart, C.; Liu, G.; Huang, C.; Kuenzer, C. A River Basin over the Course of Time: Multi-Temporal Analyses of Land Surface Dynamics in the Yellow River Basin (China) Based on Medium Resolution Remote Sensing Data. Remote Sens. 2016, 8, 186. [CrossRef]

32. De Keersmaecker, W.; Lhermitte, S.; Hill, M.J.; Tits, L.; Coppin, P.; Somers, B. Assessment of Regional Vegetation Response to Climate Anomalies: A Case Study for Australia Using GIMMS NDVI Time Series between 1982 and 2006. Remote Sens. 2017, 9, 34. [CrossRef]

33. Gogoi, P.P.; Vinoj, V.; Swain, D.; Roberts, G.; Dash, J.; Tripathy, S. Land use and land cover change effect on surface temperature over Eastern India. Sci. Rep. 2019, 9, 8859. [CrossRef] [PubMed]

34. Liu, X.F.; Yang, Y.; Ren, Z.Y.; Lin, Z.H. Changes of Vegetation Cover age in the Loess Plateau in 2000-2009. J. Desert Res. 2013, 33, 1244-1249. [CrossRef]

35. McKeon, G.M.; Stone, G.S.; Syktus, J.I.; Carter, J.O.; Flood, N.R.; Ahrens, D.G.; Howden, S.M.; Johnston, P.W.; Ryan, J.G.; Day, K.A.; et al. Climate change impacts on northern Australian rangeland livestock carrying capacity-a review of issues. Rangel. J. 2009, 31, 1-29. [CrossRef]

36. Ahlström, A.; Raupach, M.R.; Schurgers, G.; Smith, B.; Arneth, A.; Jung, M.; Reichstein, M.; Canadell, J.G.; Friedlingstein, P.; Jain, A.K.; et al. The dominant role of semi-arid ecosystems in the trend and variability of the land $\mathrm{CO}_{2}$ sink. Science 2015, 348, 895-899. [CrossRef]

37. Guerschmana, J.P.; Hill, M.J.; Leys, J.; Heidenreich, S. Vegetation cover dependence on accumulated antecedent precipitation in Australia-Relationships with photosynthetic and non-photosynthetic vegetation fractions. Remote Sens. Environ. 2020, 240, 111670. [CrossRef]

38. Amiri, R.; Weng, Q.H.; Alimohammadi, A.; Alavipanah, S.K. Spatial-temporal dynamics of land surface temperature in relation to fractional vegetation cover and land use/cover in the Tabriz urban area, Iran. Remote Sens. Environ. 2009, 113, $2606-2617$. [CrossRef]

39. Gao, X.; Zhao, Q.; Zhao, X.; Wu, P.; Pan, W.; Gao, X.; Sun, M. Temporal and spatial evolution of the standardized precipitation evapotranspiration index (SPEI) in the Loess Plateau under climate change from 2001 to 2050. Sci. Total. Environ. 2017, 595, 191-200. [CrossRef]

40. Arneth, A. Climate science: Uncertain future for vegetation cover. Nature 2015, 524, 44-45. [CrossRef] [PubMed]

41. Sun, X.P.; Wang, T.M.; Kou, X.J.; Ge, J.P. Normalized difference vegetation index dynamic change and its driving factor analysis with long time series in the Jinghe River watershed on the Loess Plateau of China. Chin. J. Plant Ecol. 2012, 36, 511-521. [CrossRef]

42. Zhi, T.; Zhang, H.B.; Xin, C.; Wei, X.C.; Dang, C.H. Vegetation cover variation and its impact on runoff in Tuweihe River Watershed. Water Resour. Hydropower Eng. 2021, 02, 40-52.

43. Dong, X.; Chen, Z.; Wu, M.; Hu, C. Long time series of remote sensing to monitor the transformation research of Kubuqi Desert in China. Earth Sci. Inf. 2020, 13, 795-809. [CrossRef]

44. Ostwald, M.; Chen, D. Land-use change: Impacts of climate variations and policies among small-scale farmers in the Loess Plateau, China. Land Use Policy 2006, 23, 361-371. [CrossRef]

45. Chen, C.; Park, T.; Wang, X.; Piao, S.; Xu, B.; Chaturvedi, R.K.; Fuchs, R.; Brovkin, V.; Ciais, P.; Fensholt, R.; et al. China and India lead in greening of the world through land-use management. Nat. Sustain. 2019, 2, 122-129. [CrossRef]

46. Yang, W.; Pei, J.; Li, X.X.; Sun, T.; Wang, W.Y. Effect evaluation and management strategies for freshwater restoration projects in Yellow River Delta wetlands. J. Beijing Norm. Univ. (Nat. Sci.) 2018, 54, 98-103. [CrossRef]

47. Sun, Q.L.; Li, B.L.; Xu, L.L.; Tao, Z.; Jinsong, G.; Fei, L. Analysis of NDVI change trend and its impact factors in the Three-River Headwater Region from2000 to 2013. J. Geo-Inf. Sci. 2016, 18, 1707-1716. [CrossRef]

48. Liu, R.G.; Liu, Y. Generation of new cloud masks from MODIS land surface reflectance products. Remote Sens. Environ. 2013, 133, 21-37. [CrossRef]

49. Chen, J.M.; Deng, F.; Chen, M. Locally adjusted cubic-spline capping for reconstructing seasonal trajectories of a satellite-derived surface parameter. IEEE Trans. Geosci. Remote Sens. 2006, 44, 2230-2238. [CrossRef]

50. Liu, R.; Shang, R. Global evaluation of gap-filling approaches for seasonal NDVI with considering vegetation growth trajectory, protection of key point, noise resistance and curve stability. Remote Sens. Environ. 2017, 89, 164-179. [CrossRef]

51. Ministry of Ecology and Environment, China; Chinese Academy of Sciences. Eco-Environment Investigation and Assessment from 2000 to 2010 with Remote Sensing of China; Science Press: Beijing, China, 2014. 
52. McNally, A.; Arsenault, K.; Kumar, S.; Shukla, S.; Peterson, P.; Wang, S.; Funk, C.; Peters-Lidard, C.D.; Verdin, J.P. A land data assimilation system for sub-Saharan Africa food and water security applications. Sci. Data 2017, 4, 170012. [CrossRef] [PubMed]

53. Abatzoglou, J.T.; Dobrowski, S.; Parks, S.A.; Hegewisch, K.C. TerraClimate, a high-resolution global dataset of monthly climate and climatic water balance from 1958-2015. Sci. Data 2018, 5, 170191. [CrossRef] [PubMed]

54. Mann, H.B. Non-parametric Tests against Trend. Econometrica 1945, 13, 245-259. [CrossRef]

55. Deng, X.Y.; Liu, Y.; Liu, Z.H.; Yao, J.Q. Temporal-spatial dynamic change characteristics of evapotranspiration in arid region of Northwest China. Acta Ecol. Sin. 2017, 37, 2994-3008. [CrossRef]

56. Zoungrana, B.J.-B.; Conrad, C.; Thiel, M.; Amekudzi, L.K.; Da, E.D. MODIS NDVI trends and fractional land cover change for improved assessments of vegetation degradation in Burkina Faso, West Africa. J. Arid. Environ. 2018, 153, 66-75. [CrossRef]

57. Smith, L.C. Trends in Russian Arctic river-ice formation and breakup, 1917 to 1994. Phys. Geogr. 2000, 21, 46-56. [CrossRef]

58. Wessels, K.J.; Bergh, F.V.D.; Scholes, R.J. Limits to detectability of land degradation by trend analysis of vegetation index data. Remote Sens. Environ. 2012, 125, 10-22. [CrossRef]

59. Yao, J.; Wang, M.; Huang, Y.C.; Bai, Y.; Huang, S.F. Three-dimensional frame exploration of the ecological protection red line in China: A case study of the Ningde region. Acta Ecol. Sin. 2015, 35, 6848-6856. [CrossRef]

60. Liu, Y.; Li, D.L.; Yang, T.Z. Study on the Influence of Geographical Indication Cognition on Farmers' Safe Production- Taking "Luochuan Apple" in Shaanxi as example. Chin. J. Agric. Resour. Reg. Plan. 2021, 42, 209-216.

61. Zhang, X.B.; Zhang, D.Y.; Shangguan, Z.P.; Mao, N. Temporal variation of driving factors for land desertification in Huan county of Gansu province from 1949 to 2013. J. Arid. Land Resour. Environ. 2016, 30, 130-135. [CrossRef]

62. Sun, Q.; Zhang, D.S.; Liu, M.; Li, K.K.; Liu, J.H. Research on the Community Characters of Restored Vegetation on Loess Plateau in Huanxian County, Gansu Province. Mod. Landsc. Archit. 2014, 11, 22-30.

63. Han, J.P. The Difficulty and Countermeasure of the New Round Returning Farmland to Forest in Huanxian County, Gansu. J. Gansu For. Sci. Technol. 2021, 46, 64-66. [CrossRef] 